\title{
Impaired acquisition of DRL operant responding following lesion of the habenular nucleus
}

\author{
J. A. C. EVANS and E. W. THORNTON \\ University of Liverpool, Liverpool, England
}

\begin{abstract}
The habenula has great diversity in both its afferent and efferent projection areas. Among the many regions supplying afferent projections to the area is one of the primary limbic structuresthe septal region, which has been linked to numerous behavioral functions, but in particular behavioral inhibition. Previous behavioral studies of the habenula have shown lesions of the struc. ture to produce deficits in the ability to alter behavior in response to both internal and external stimuli, and it may be that this deficit is subsequent to a deficit in ability to inhibit responding. To examine this possibility, the effects of lesions of the habenula on performance were examined in a paradigm frequently employed to show septal-lesion-induced deficits in response inhibitionthe DRL operant paradigm. Lesioned animals were found to show deficits-both general overresponding and an uneconomical temporal distribution of responses-in the uncued, but not the cued, DRL paradigm, effects paralleling those resulting from septal lesions. These results are discussed in terms of the relationship between septal and habenular functioning, and the many suggested causes for the deficits displayed by septal animals in the DRL paradigm.
\end{abstract}

The habenula has been suggested to provide a unique site of convergence of limbic and striatal outputs. The striatal outputs arise from the entopeduncular nucleus (globus pallidus), through which the majority of striatal influences are mediated, whereas the limbic afferents arise from many structures, including the diagonal band of Broca, nucleus accumbens, lateral preoptic area, substantia innominata, lateral hypothalamus, and septal region, and influence the habenular nucleus through the stria medullaris (Sutherland, 1982).

Among the major projection areas of the habenula are the ventral tegmental area, substantia nigra pars compacta, interpeduncular nucleus, and raphe nuclei. In view of the convergence among its afferents, the habenula has great potential for coordinating incoming striatal and limbic influences, and the diversity of its efferent projection areas enable these combined influences to affect a wide variety of behaviors. Hence, lesions to the nuclei have been shown to affect such limbic behaviors as stimulus discrimination, feeding, intracranial self-stimulation, and avoidance behaviors, and efferent connections with the substantia nigra may enable modulations by the habenula of the striatothalamo-motor-cortical system (Sutherland, 1982; Swanson, 1978).

In terms of regulation of behavioral functions, one of the most important limbic areas is the septal region, and prominent connections exist between the septal area and the habenular nuclei, in particular, the medial habenular nucleus. The exact origin, within the complex septal region of the habenular afferents is still to a large extent unclarified, but it appears that both the ventral septum

The authors' mailing address is: Department of Psychology, University of Liverpool, P.O. Box 147, Liverpool LG9 3BX, England. (bed nucleus of stria terminalis) and the posterior/ supracommissural septum (the triangular and septofimbrial nuclei) have reciprocal connections with the medial habenular nucleus, the afferents contributing a major part of the cholinergic input to the medial habenula (Swanson, 1978). In the light of this, and of the efferent projection areas of the habenular nuclei, it has been suggested that the habenula may be responsible for mediating the behavioral effects of the septal area by effecting changes in the activity of the ventral tegmental area, substantia nigra, and raphe nuclei, the sites of origin of the major dopamine and 5-HT neurotransmitter pathways in the brain (Phillipson \& Pycock, 1982; Speciale, Neckers, \& Wyatt, 1980).

In view of the dense anatomical connections between the habenula and the septohippocampal system, it was considered useful to examine the effects of lesions to the habenula on septally-regulated behavior. The septohippocampal system has been associated with a wide variety of behavioral activities, with investigations to date providing evidence for septal-lesion-induced changes in aggression, avoidance behaviors, response to punishments, food- and water-intake regulation, and locomotor activity. A vast amount of effort has been put into attempting to formulate a unifying explanation for these diverse effects in terms of a general role of the septum in response inhibition (McCleary, 1961, 1966). Although several behavioral paradigms have been employed in attempts to provide support for such theories, many such paradigms are not pure tests of response inhibition, and hence frequently produce confused and conflicting results. The most extensively used tests of an animal's ability to inhibit nonrewarded responding-ones that have been suggested to be independent of situational changes and ac- 
quisition of new responses-are the fixed-interval (FI) and differential reinforcement of low rate of responding (DRL) schedules of reinforcement (Grossman, 1978). In the latter, reinforcements are programmed at regular intervals, by resetting the time whenever a response is made, but the animal is penalized for responses given before the required delay has elapsed. Most normal animals learn to time their responses fairly accurately, but rats with septal lesions have consistently been reported to show deficits in responding during both acquisition and retention of this schedule (Ellen, Wilson, \& Powell, 1964; Hobbs, Bunnell, \& Henke, 1976; Kelsey \& Grossman, 1971; McCleary, 1966).

Fried (1972), among others, concluded that the complexity of connections, and anatomical heterogeneity of the septal region, meant that a unitary conceptualization of function of the septum was inappropriate. Rather, different parts of the septal area, with their different afferent and projection areas are important for different behaviors. In an extensive study of the septal efferents that mediate the lesion-induced deficit in DRL performance, Ross and Grossman (1975) found that fornix transections most nearly replicated the disinhibitory effects of septal lesions in operant paradigms, whereas transections of the medial forebrain bundle did not. On the basis of this, it was concluded that septohippocampal fibre transections are of greatest importance in causing septal lesions' disinhibitory effects in DRL operant paradigms. This conclusion is now widely accepted (Carey, 1968).

In earlier studies of the behavioral effects of transections of different septal connections, Ross (1974) found that transections of the stria medullaris led to only slight and transitory disinhibitory effects in a DRL operant schedule, as opposed to the massive and persistent deficits seen after either septal or total fornix lesions. These results agreed with those of MacDougall, Van Hoesen, and Mitchell (1969), who, with regard to retention of DRL responding, found stria medullaris transections to produce a level of deficit midway between the gross deficits resulting from total fornix lesions and the negligible effects of medial fornix lesions. They, too, found this stria medullaris transection-induced deficit to be only transitory in as much as it disappeared by the 6th postoperative day.

Other studies, however, have reported lesions of the habenula to have a dramatic effect on inhibitory tendencies (e.g., Van Hoesen, MacDougall, \& Mitchell, 1969). Although in this instance Grossman (1976) considers the lesion effects to be due to interruption of the habenulointerpeduncular connections rather than septohabenular (stria medullaris) connections, this remains a matter of debate. Ross (1974) produced results showing lesions of the stria medullaris to produce deficits, in a one-way active avoidance paradigm, similar to septal lesion deficits, whereas neither lesion is found to affect performance in two-way active avoidance paradigms. From such results, it becomes obvious that there is a great deal of ambiguity in the evidence concerning the relationship between sep- tal and habenular functioning and in the apportioning of septal functions to the region's efferent pathways.

The present study was thus designed to examine the effects of lesions of the habenular nuclei on the acquisition of operant responding under a DRL schedule. As an extension to this study, a comparison was made between the performance of rats in cued versus uncued DRL paradigms. Several earlier studies have shown septallesioned rats to perform at normal levels in cued DRL schedules despite exhibiting dramatic deficits in the uncued form (Braggio \& Ellen, 1976; Caplan \& Stamm, 1967; Ellen \& Butter, 1969; Lubar \& Numan, 1973). Several suggestions have been made to explain the cause of this differential performance; for example, the uncued DRL is a more difficult task and hence would be more sensitive to behavioral deficits of a general learning type (Pellegrino \& Clapp, 1971). An alternative theory, however, suggests that septal animals fail to utilize differential internal stimuli as discriminative cues for behavior (Caplan, 1973; Ellen \& Butter, 1969; Fried, 1972; Hobbs et al. 1976; Lubar \& Numan, 1973; MacDougall et al. 1969). Since successful performance in uncued DRL paradigms necessitates utilization of such cues, animals could be expected to be deficient; on the other hand, in cued DRL paradigms, in which exteroceptive stimuli are available to guide behavior, the levels of performance could be expected to be normal. By employing both cued and uncued DRL schedules in the present study, we hoped to determine whether a differential performance similar to that of septal-lesioned animals would be found following lesions of the habenula.

\section{METHOD}

Twenty male Lister hooded rats weighing $511.5 \pm 36 \mathrm{~g}$ (weight prior to reduction) were reduced to $80 \%$ free-feeding weight and housed singly in a room maintained on a 12-hour light/dark cycle. Following leverpress training, the animals were matched on weight, with one animal of each pair receiving a bilateral lesion of the habenular nuclei and the other undergoing sham operative procedures. All operations were performed under sodium pentobarbital anesthesia (Nembutal $50 \mathrm{mg} / \mathrm{kg}$ ip) with an additional injection of $0.2 \mathrm{cc}$ atropine sulfate to reduce respiratory distress. The animals were positioned in a Kopf stereortaxic frame, with lesion coordinates taken from the atlas of Pellegrino and Cushman (1967), at A-P $=+3.6$; Lat $= \pm 0.6 ; \mathrm{H}=+0.7$. Lesions were made by passing an RF current of $7 \mathrm{~mA}$ for $12 \mathrm{sec}$ from a Grass Model LM4 lesion maker, through an insulated stainless steel electrode with an exposed tip of $0.4 \mathrm{~mm}$. Sham animals received the same operative procedures, but no current was passed through the electrode. Operant training sessions were carried out in standard, sound-attenuated operant chambers (Coulbourn Instruments Ltd.) with reinforcement provided by delivery of a standard $45-\mathrm{mg}$ food pellet. Stimulus presentation and response collection was made by an ACT N computing system (Campden Instruments Ltd.) housed in a different room.

The animals were preoperatively trained to leverpress in 18 daily sessions on a CRF schedule, until all animals were receiving 200 reinforcements per session. After being allowed to recover for 5 days following the operation, the animals were given two further 30 -min training sessions on a CRF schedule. They were then transferred to the uncued DRL 20 -sec operant schedule. On this schedule, reinforcement was given for the first response made following completion of a 20 -sec period of nonresponding. No upper limit occurred for delay of a response beyond 
the 20 -sec period to achieve reinforcement, but responses given within the 20 -sec period reset the delay required to $20 \mathrm{sec}$.

Following 53 daily $30-\mathrm{min}$ sessions on this schedule, the animals were transferred to a cued DRL 20 -sec schedule, for a further eight daily 30 -min training sessions. On this cued schedule, three lights on the operant chamber wall, above the levers and food well, were lit up upon completion of the 20-sec delay period.

All animals were tested between 0900 and $1400 \mathrm{~h}$ and fed a few hours after completion of training sessions.

Following completion of all the operant testing, the animals were sacrificed and their brains were removed and stored in sucro-Formalin. To determine the site and extent of lesions, frozen sections of the brains, $50 \mu \mathrm{m}$ thick, were subjected to histological examination.

\section{RESULTS}

\section{Data Analysis}

In accordance with Kramer and Rilling's (1970) detailed critique of DRL performance, a complete analysis of performance on a DRL operant schedule necessitates examinations of both response and reinforcement rates, and a measure expressing the number of reinforced responses as a percentage of the total number of responses-the efficiency ratio. In addition, IRT analyses were performed in terms of both the percentage distribution of responses between successive time bins and an IRTs/Op analysis (IRTs per opportunity). This latter statistic is considered to be a more sensitive measure of temporal discrimination, since it takes into account the differing number of opportunities to respond in the differing IRTs.

Statistical analyses were performed by use of ANOVA, with significant $F$ ratios being subjected to further analysis by Tukey's HSD test. Results of these tests are presented in Table 1.

\section{Uncued DRL}

The changes in behavior over sessions for each of the dependent variables is presented in Figures 1 and 2. A conspiciously high response rate, and reinforcement rate due to the intermittent pattern of responding, was evident for the first 3 days on the DRL schedule. This may have been a direct consequence of the sudden changeover from CRF to DRL schedules on consecutive sessions. The level of performance on these first few days failed to fit in with the general trend shown over later sessions and may be considered as unrepresentative of performance in repeated exposure to DRL training sessions. Hence, although data from these first 3 days are included in the graphs and statistical analyses, descriptions of the data are confined to performance from the fourth training session onwards.

Lesioned animals showed a general impairment in performance relative to controls, emitting a higher response rate $(p<.01)$, thereby achieving fewer reinforcements $(p<.01)$ and hence having a lower efficiency ratio $(p$ $<.05$ ). Although both groups did show some degree of improvement over sessions, this was far greater for sham animals. Consequently, although on the first session lesion and sham groups had similar performance levels, on the last uncued session sham animals gained significantly more reinforcements $(p<.01)$ and had a better efficiency ratio $(\mathrm{p}<.01)$.

Both IRT distribution analyses confirm the similarity in performance of sham and lesion groups during the first few sessions, with neither group showing any evidence of temporal discrimination. By the final few sessions, although both groups were showing some evidence of such discriminations, they differed as to the mean duration of

Table 1

Significant Results of Statistical Analyses of Behavioral Measures

\begin{tabular}{|c|c|c|c|c|c|c|c|}
\hline \multirow[b]{2}{*}{ Measure } & \multicolumn{4}{|c|}{ ANOVA } & \multicolumn{3}{|c|}{ Tukey's Test } \\
\hline & Effect & $\mathbf{F}$ & df & Sig & Effect & qoBs & Sig \\
\hline \multicolumn{8}{|c|}{ Uncued } \\
\hline Reinforcements & $\begin{array}{l}\text { Lesion } \\
\text { Days } \\
\text { Lesion } \times \text { Days }\end{array}$ & $\begin{array}{r}11.76 \\
8.03 \\
3.40\end{array}$ & $\begin{array}{c}1,16 \\
52,832 \\
52,832\end{array}$ & $\begin{array}{l}1 \% \\
1 \% \\
1 \%\end{array}$ & $\begin{array}{l}\text { L v S } \\
\text { Days } 1 \text { v } 53 \\
\text { Day } 53 \text { L v S }\end{array}$ & $\begin{array}{l}4.85 \\
8.50 \\
7.19\end{array}$ & $\begin{array}{l}1 \% \\
1 \% \\
1 \%\end{array}$ \\
\hline Responses & $\begin{array}{l}\text { Lesion } \\
\text { Days } \\
\text { Lesion } \times \\
\text { Days }\end{array}$ & $\begin{array}{r}20.95 \\
17.61 \\
1.39\end{array}$ & $\begin{array}{c}1,16 \\
52,832 \\
\\
52,832\end{array}$ & $\begin{array}{l}1 \% \\
1 \% \\
5 \%\end{array}$ & $\begin{array}{l}L \vee S \\
\text { Days } 1 \text { v } 53\end{array}$ & $\begin{array}{l}6.47 \\
7.26\end{array}$ & $\begin{array}{l}1 \% \\
1 \%\end{array}$ \\
\hline Efficiency Ratio & $\begin{array}{l}\text { Lesion } \\
\text { Days } \\
\text { Lesion } \times \text { Days }\end{array}$ & $\begin{array}{l}8.20 \\
4.28 \\
2.94\end{array}$ & $\begin{array}{c}1,16 \\
52,832 \\
52,832\end{array}$ & $\begin{array}{l}5 \% \\
1 \% \\
1 \%\end{array}$ & $\begin{array}{l}\text { L v S } \\
\text { Day } 53 \mathrm{~L} \text { v S }\end{array}$ & $\begin{array}{l}4.05 \\
6.43\end{array}$ & $\begin{array}{l}5 \% \\
1 \%\end{array}$ \\
\hline \multicolumn{8}{|c|}{ Cued } \\
\hline Reinforcements & $\begin{array}{l}\text { Days } \\
\text { Lesion } \times \text { Days }\end{array}$ & $\begin{array}{l}53.98 \\
13.24\end{array}$ & $\begin{array}{l}7,112 \\
7,112\end{array}$ & $\begin{array}{l}1 \% \\
1 \%\end{array}$ & $\begin{array}{l}\text { Day } 1 \vee 8 \\
\text { Day } 1 \mathrm{~L} \vee \mathrm{S}\end{array}$ & $\begin{array}{r}20.93 \\
5.26\end{array}$ & $\begin{array}{l}1 \% \\
1 \%\end{array}$ \\
\hline Responses & $\begin{array}{l}\text { Lesion } \\
\text { Days } \\
\text { Lesion } \times \text { Days }\end{array}$ & $\begin{array}{r}8.33 \\
41.04 \\
13.10\end{array}$ & $\begin{array}{l}1,16 \\
7,112 \\
7,112\end{array}$ & $\begin{array}{l}5 \% \\
1 \% \\
1 \%\end{array}$ & $\begin{array}{l}\text { L v } \\
\text { Day } 1 \text { × } 8 \\
\text { Day } 1 \text { L } v S\end{array}$ & $\begin{array}{r}4.08 \\
19.57 \\
8.13\end{array}$ & $\begin{array}{l}5 \% \\
1 \% \\
1 \%\end{array}$ \\
\hline Efficiency Ratio & $\begin{array}{l}\text { Days } \\
\text { Lesion } \times \text { Days }\end{array}$ & $\begin{array}{r}47.20 \\
8.72 \\
\end{array}$ & $\begin{array}{l}7,112 \\
7,112 \\
\end{array}$ & $\begin{array}{l}1 \% \\
1 \% \\
\end{array}$ & Day 1 v 8 & 20.15 & $1 \%$ \\
\hline
\end{tabular}




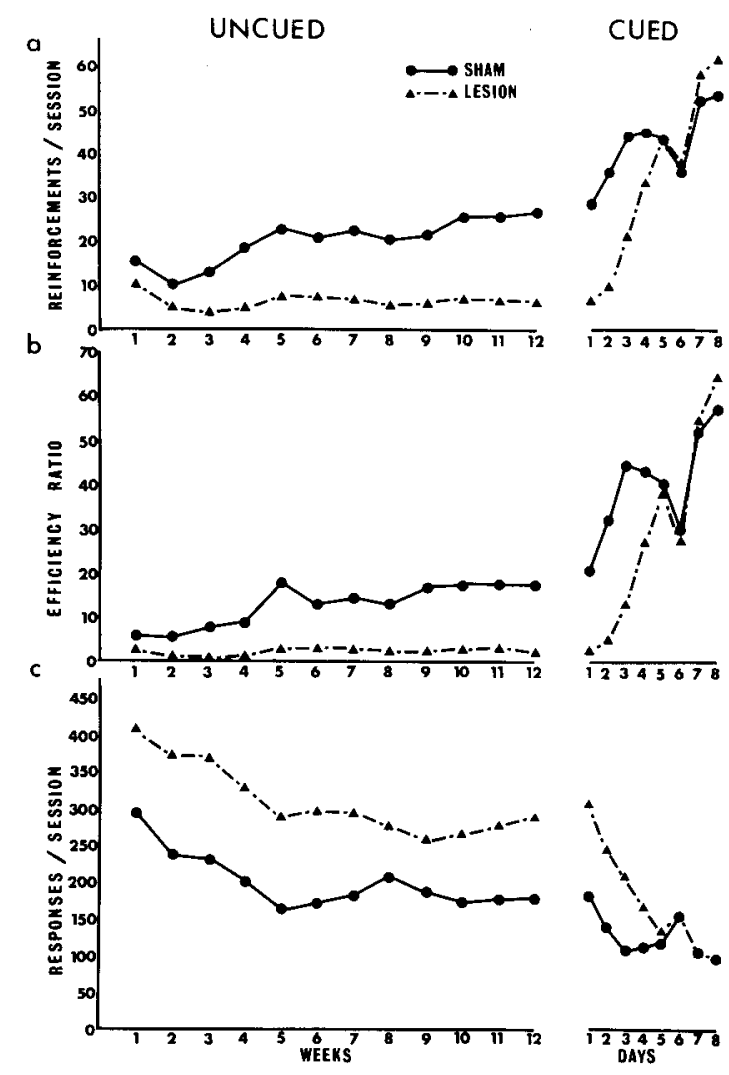

Figure 1. Performance of lesioned and control groups in uncued and cued DRL 20 sec over weeks and days, respectively. (a) Mean number of reinforcements obtained per 30-min session. (b) Mean efficiency ratio per session. (c) Mean number of responses made per session.

their responses. Thus, from the percentage IRT distribution analysis, sham animals can be seen to have produced an increased frequency of responding in the 18-20-sec delay period, consistent with schedule requirements. For lesioned animals, however, it fell in the 8-10-sec delay period, which is suggestive of a poor level of temporal discrimination or a deficit in ability to withhold responding. These conclusions were confirmed by the IRTs/Op analysis. The graph (Figure 3 ) for the final uncued sessions shows a gradual rise in probability from 4-6-sec delay for the sham group up to and beyond the 20-sec mark, which is consistent with temporal discrimination. The lesioned group, although similarly showing a rise up to and beyond the 20 -sec mark, actually peaked below the critical reinforced delay period and also showed a higher probability at all delay periods below $20 \mathrm{sec}$, again suggesting a lower level of temporal discrimination relative to controls.

\section{Cued DRL}

Although a lesion effect was still found for response rate, lesion and sham groups regained similar levels of performance in terms of reinforcement rate and efficiency ratio. Both groups showed an improvement over sessions, more so for the lesioned group, such that although on the first session sham animals received a greater number of reinforcements $(p<.01)$ and emitted a lower response rate $(\mathrm{p}<.01)$, by the final session the groups were equivalent in performance, Hence, no significant lesion effect was found for either reinforcement rate or efficiency rate or efficiency ratio. Although lesioned animals were still found to have a higher response rate $(p<.05)$, this was due mainly to the large difference between lesion and sham groups on the first session of cued DRL training, response rates on the final session being identical for the two groups.

\section{Histology}

On the basis of histological examination of frozen sections taken from the brains of the subjects, one lesioned animal was rejected because the lesion was very small and medial. In the other animals, lesions did often appear to extend ventrally into the periventricular nucleus, but in no animals did lesions intrude into either the hippocampus or dorsomedial thalamus. On the whole, the lesions were slightly caudal, the stria medullaris remaining intact in all animals. Examples of the lesions are shown in Figure 4.

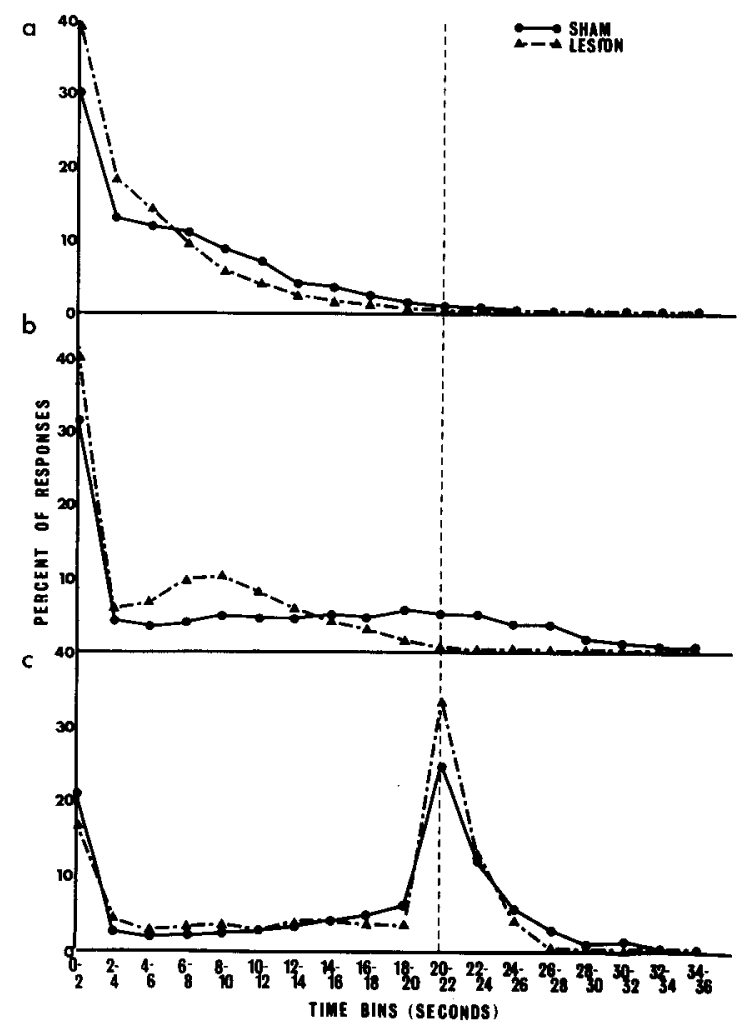

Figure 2. Mean relative frequency of responses produced in each 2-sec IRT category for lesioned and control groups during DRL 20-sec. (a) Fourth session on uncued DRL. (b) Final session of uncued DRL. (c) Final session of cued DRL. 


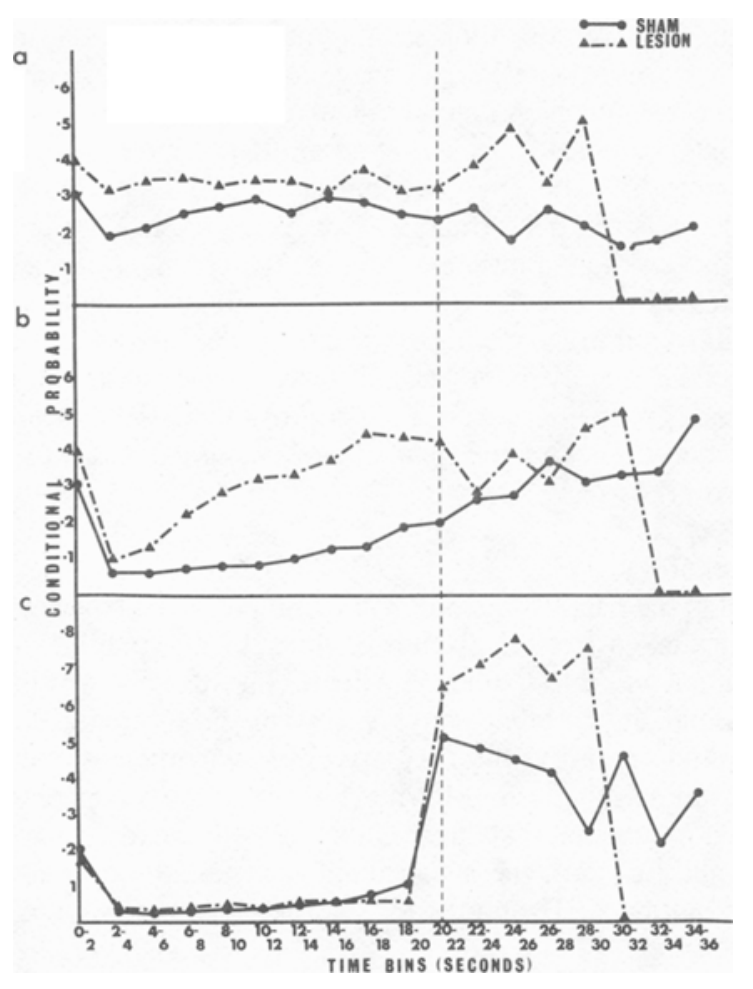

Figure 3. Mean response probability for lesioned and control groups during DRL 20 sec. (a) Fourth session of uncued DRL. (b) Final session of uncued DRL. (c) Final session of cued DRL.

One sham animal was lost during surgery, so the data used in analysis were derived from nine lesion and nine control animals.

\section{DISCUSSION}

The results demonstrate that in the absence of an external cue to guide behavior, animals with lesions of the habenular nucleus show severely impaired acquisition and performance on DRL operant schedules, deficits which seemingly arise from an inability to inhibit responding and a failure to develop temporal discrimination. Following the introduction of an external cue, both lesioned and sham animals improved their level of performance to a large extent, with lesioned animals developing reinforcement and response rates and an efficiency ratio equal to those of sham animals by the eighth session cued DRL.

This differential performance of lesioned animals on cued versus uncued DRL parallels results obtained by Caplan and Stamm (1967), Ellen and Butter (1969), and others, using septal lesions and by Pellegrino and Clapp (1971) using basolateral amygdala and hippocampal lesions. In the light of this, it could be possible that amygdala, hippocampal, and habenular lesions all produce deficits in uncued DRL performance for the same reason as has been suggested for septal deficits, that is, that such animals are unable to utilize differential internal stimuli as discriminative cues for behavior. However, proof that the deficits resulting from limbic lesions and lesions of the habenula do indeed have a common underlying basis has yet to be obtained.

Although the present results can be related to those produced following lesions of other limbic areas, they appear to conflict with the results of both MacDougall et al. (1969) and Ross (1974), who found transections of the stria medullaris to produce only slight and transitory deficits in DRL performance. Histological examination of the brains of animals used in the present study revealed no damage to the overlying hippocampus; hence, the findings of a large and permanent DRL responding deficit cannot be attributed to the direct disruption of hippocampal functioning. Similarly, no damage was found to the habenulointerpenduncular tract, the pathway Grossman (1976) considered to be responsible for the effects, found by Van Hoesen et al. (1969), of lesions of the habenula on avoidance behaviors, although such lesions would have undoubtedly have affected the functioning of the

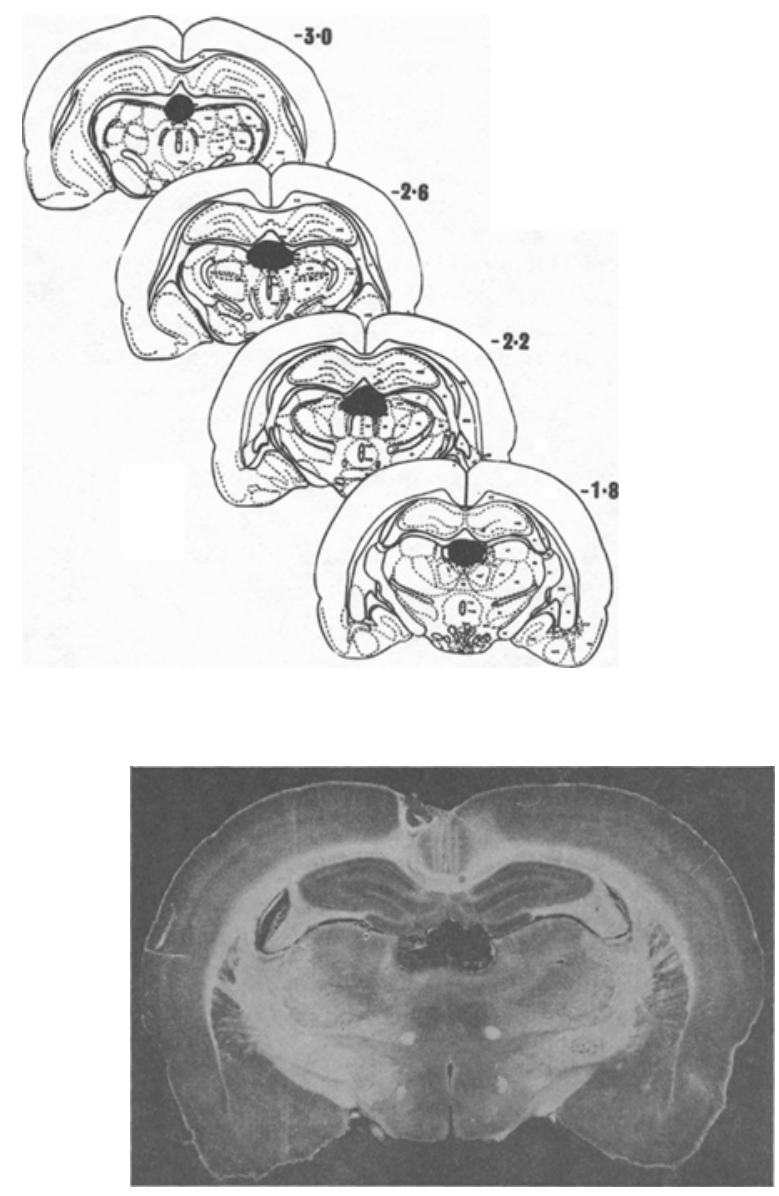

Figure 4. (a) Diagrammatic representation of the size and location of bilateral electrolytic lesions of the habenula nucleus. Black shading represents area of tissue damage. (b) Photograph of brain section showing typical lesion of the habenula nucleus. 
habenulointerpeduncular tract, to a similar extent as all other habenular efferents.

A possible explanation for the apparent confliction in the results may lie in the fact that MacDougall et al. (1969), and also possibly Ross (1974), were examining the effects of habenular lesions on retention of DRL performance as opposed to effects on the acquisition of responding examined in this study. Ross also used a slightly modified form of the DRL operant paradigm in which animals received no operant training prior to the introduction of the DRL contingencies, and were also required to make successive responses on different levers. These differences in experimental technique could, in some way, have made the task easier for habenular lesioned rats, so reducing lesion-inducing deficits.

On the basis of studies of the septal efferents involved in various septal lesion effects, Ross (1974) and Grossman (1978) concluded that the stria medullaris (septohabenula) pathway was of little importance in the DRL deficits seen to follow septal lesions. The results produced in the present study contradict this conclusion; they suggest that the habenular nucleus is involved in DRL responding, and they implicate the stria medullaris.

However, an alternative explanation for the present results could be made by recourse to neostriatal functioning. Striatal lesions have frequently been reported to disrupt DRL performance (e.g., Dunnett \& Iversen, 1982; Neill, Ross, \& Grossman, 1974; Schmaltz \& Isaacson, 1968), producing an inefficient distribution of responding (shown by an elevated response rate at short IRTs followed by a decline to a low conditional probability of responding at longer, reinforced IRTs) and/or an overall increase in response rate. Septal lesions are more usually associated just with this latter form of deficit-said to indicate an inability to withhold responding-rather than the former type, which indicates deficient temporal discrimination. Because, in this study, habenular lesions appeared to produce both these forms of deficit, it could be that the lesion effects were mediated via disruption of striatal modulation of DRL responding instead of, or in addition to, disruption of septal modulatory influences.

Consideration should also be given to proposals that deficits in DRL performance do not necessarily imply a deficit in either temporal discrimination or ability to inhibit responding. Suggestions have been made that since septal animals are able to overcome their DRL deficit in the uncued paradigm under certain experimental conditions-for example, gradual fading of cue light (Ellen, Dorsett, \& Richardson, 1977), gradual lengthening of the DRL delay (Caplan \& Stamm, 1967), provision of a wooden block or cardboard to chew on during the delay (Slonaker \& Hothersall, 1972), or altering the force required to depress the lever as a function of time since the last response (Braggio \& Ellen, 1974)-deficits in response inhibition are not a primary symptom of septal damage, but rather, are secondary to some other form of deficit. Kramer and Rilling (1970) suggest that successful performance on DRL does not require acquisition of temporal discriminations, that animals could equally well learn to pace responding by emitting chains of "mediating" or "superstitious" behaviors, that is, learn that, to achieve reinforcement, responses must be separated not by a particular time span, but rather by performance of a set sequence of behavioral acts, an idea that forms the basis of the DRO (differential reinforcement of other behaviors) theory of DRL responding. That animals may, indeed, use such means to guide their responding is suggested by findings that drugs that upset performance of sequences of superstitious behavior also upset performance on DRL schedules. Since previous studies (Thornton \& Evans, 1982) have shown animals with lesions of the habenula to be deficient in sequencing behavioral acts, use of this strategy to guide DRL responding would be expected to result in impaired performance. However, since other studies have reported an ability of animals to learn DRL schedule requirements without developing any recognizable overt behavioral chains, it may be that such behavioral sequences are not necessary in every animal for it to learn DRL, so reliance on internal temporal stimuli to guide behavior must occur in at least some animals.

\section{CONCLUSION}

Lesions of the habenular nuclei in rats produce deficits in performance on DRL schedules that resemble the deficits seen to result from lesions to both other limbic regions, that is, the septum, amygdala, and hippocampus and the neostriatum. Deficits in such animals are shown both in general ability to inhibit responding and in temporal organization of responding on uncued DRL schedules as contrasted with the normal levels of performance shown on cued DRL schedules. Many doubts exist as to the possible cause for this deficit in cued DRL: does it result from deficiencies in acquisition of temporal discrimination, in ability to inhibit responding, or in ability to perform sequences of "mediating"' behavioral acts, or, indeed, from none of these? It has yet to be determined whether behavioral effects are due to disruption of striatal or septal influences over DRL responding, or whether influences from both regions are involved. Certainly, the data, in contradiction to previous suggestions, implicate the habenula, and the subsequent behavior topography suggests that the disruption in performance is not simply a consequence of damage to septal efferents.

\section{REFERENCES}

Braggio, J. T., \& Ellen, P. (1974). Differential proprioceptive feedback and DRL performance of normal and septal rats. Journal of Comparative and Physiological Psychology, 87, 80-89.

Braggio, J. T., \& Ellen, P. (1976). Cued DRL training: Effects on the permanence of lesion-induced overresponding. Journal of Comparative and Physiological Psychology, 90, 694-703.

CAPLAN, M. (1973). An analysis of the effects of septal lesions on negatively reinforced behavior. Behavioral Biology, 9, 129-167.

CAPLAN, M., \& STAMM, J. (1967). DRL Acquisition in rats with septal lesions. Psychonomic Science, 8, 5-6. 
Carey, R. J. (1968). A further localization of inhibitory deficits resulting from septal ablation. Physiology \& Behavior, 3, 645-649.

DunNeTt, S. B., \& IVERSEN, S. D. (1982). Neurotoxic lesions of ventrolateral but not anteromedial neostriatum in rats impair differential reinforcement of low rates (DRL) performance. Behavioural Brain Research, 6, 213-226.

Ellen, P., \& BUTTER, J. (1969). External cue control of DRL performance in rats with septal lesions. Physiology \& Behavior, 4, 1-6.

Ellen, P., DorsetT, P. G., \& Richardson, W. K. (1977). The effect of cue-fading on the DRL performance of septal and normal rats. Physiological Psychology, 5, 469-476.

Ellen, P., Wilson, A. S., \& Powell, E. W. (1964). Septal inhibition and timing behavior in the rat. Experimental Neurology, 10, 120-132.

FrIED, P. A. (1972). Septum and behavior: A review. Psychological Bulletin, 78, 292-310.

Grossman, S. P. (1976). Behavioral functions of the septum: A reanalysis. In J. F. De France (Ed.), Advances in behavioral biology (Vol. 20, pp. 361-422). New York: Plenum Press.

Grossman, S. P. (1978). An experimental dissection of the septal syndrome. In Ciba Foundation Symposium 58: Functions of the septohippocampal system. Amsterdam: Elsevier/Excerpta Medica/NorthHolland.

Hobbs, S. H., Bunnell, B. N., \& Henke, P. G. (1976). Responsecontingent stimuli and DRL performance after septal lesions in rats. Brain Research Bulletin, 1, 453-458.

Kelsey, J. E., \& Grossman, S. P. (1971). Nonperseverative disruption of behavioral inhibition following septal lesions in rats. Journal of Comparative and Physiological Psychology, 75, 302-311.

Kramer, T. J., \& Rilling, M. (1970). Differential reinforcement of low rates: A selective critique. Psychological Bulletin, 74, 225-254.

LUBAR, J. F., \& NumAN, R. (1973). Behavioral and physiological studies of septal function and related medial cortical structures. Behavioral Biology, 8, 1-25.

MacDougall, J. M., Van Hoesen, G. W., \& Mitchell, J. C. (1969). Anatomical organization of septal projections in maintenance of DRL behaviour in rats. Joumal of Comparative and Physiological Psychology, 68, 568-575.

MCCLEARY, R. A. (1961). Response specificity in the behavioral effects of limbic system lesions in the cat. Journal of Comparative and Physiological Psychology, 54, 605-613.

McClearY, R. A. (1966). Response modulating functions of the limbic system: Initiation and suppression. In E. Stellar \& J. Sprague (Eds.), Progress in physiological psychology (Vol. 1). New York: Academic Press.
Neill, D. B., Ross, J. F., \& Grossman, S. P. (1974). Comparison of the effects of frontal, striatal, and septal lesions in paradigms thought to measure incentive motivation or behavioral inhibition. Physiology \& Behavior, 13, 297-305.

Pellegrino, L. J., \& Clapp, D. F. (1971). Limbic lesions and externally cued DRL performance. Physiology \& Behavior, 7, 863-868.

Pellegrino, L. J., \& Cushman, A. J. (1967). A stereotaxic atlas of the rat brain. New York: Appleton-Century-Crofts.

Phillipson, O. T., \& Pycock, C. J. (1982). Dopamine neurons of the ventral tegmentum project to both medial and lateral habenula. Some implications for habenular functions. Experimental Brain Research, 45, 89-94.

Ross, J. F. (1974). A neuroanatomical analysis of the septal lesion syndrome. Unpublished doctoral dissertation, University of Chicago.

Ross, J. F., \& Grossman, S. P. (1975). Septal influences on operant responding. Journal of Comparative and Physiological Psychology, 89, 523-536.

SchmaltZ, L. W., \& IsaAcson, R. L. (1968). Effects of caudate and frontal lesions on retention and relearning of a DRL schedule. Journal of Comparative and Physiological Psychology, 65, 343-348.

SlonAKER, R. L., \& Hothersall, D. (1972). Collateral behaviors and the DRL deficit of rats with septal lesions. Journal of Comparative and Physiological Psychology, 80, 91-96.

Speciale, S. G., Neckers, L. M., \& Wyatt, R. J. (1980). Habenular modulations of raphe indoleamine metabolism. Life Sciences, 27, 2367-2372.

SutherLand, R. J. (1982). The dorsal diencephalic conduction system: A review of the anatomy and functions of the habenular complex. Neuroscience and Biobehavioral Reviews, 6, 1-13.

Swanson, L. W. (1978). The anatomical organization of septohippocampal projections. In Ciba Foundation Symposium 58: Functions of the septohippocampal system. Amsterdam: Elsevier/Excerpta Medica/North-Holland.

Thornton, E. W., \& Evans, J. C. (1982). The role of habenular nuclei in the selection of behavioral strategies. Physiological Psychology, 10, 361-367.

Van Hoesen, G. W., MacDougall, J. M., \& Mrtchell, J. C. (1969). Anatomical specificity of septal projections in active and passive avoidance behavior in rats. Joumal of Comparative and Physiological Psychology, 68, 80-89.

(Manuscript received March 18, 1984: revision accepted for publication June 26, 1984.) 